\title{
Weight change in control group participants in behavioural weight loss interventions: a systematic review and meta-regression study
}

\author{
Lauren Waters ${ }^{1 * \dagger}$, Alexis St George ${ }^{2 \dagger}$, ${\text { Tien } \text { Chey }^{2+} \text { and Adrian Bauman }}^{2 \dagger}$
}

\begin{abstract}
Background: Unanticipated control group improvements have been observed in intervention trials targeting various health behaviours. This phenomenon has not been studied in the context of behavioural weight loss intervention trials. The purpose of this study is to conduct a systematic review and meta-regression of behavioural weight loss interventions to quantify control group weight change, and relate the size of this effect to specific trial and sample characteristics.

Methods: Database searches identified reports of intervention trials meeting the inclusion criteria. Data on control group weight change and possible explanatory factors were abstracted and analysed descriptively and quantitatively.

Results: 85 trials were reviewed and 72 were included in the meta-regression. While there was no change in control group weight, control groups receiving usual care lost $1 \mathrm{~kg}$ more than control groups that received no intervention, beyond measurement.

Conclusions: There are several possible explanations why control group changes occur in intervention trials targeting other behaviours, but not for weight loss. Control group participation may prevent weight gain, although more research is needed to confirm this hypothesis.
\end{abstract}

\section{Background}

The increasing prevalence of overweight and obesity has become a cause for concern over the past decade [1] with overweight and obesity being major determinants of a number of chronic health conditions including hypertension, cardiovascular disease, diabetes and cancer [2]. The importance of implementing interventions to address this public health problem has been recognised by the World Health Organization $[1,3]$ and the US Surgeon General [4]. Consequently, there is now an extensive body of literature addressing the efficacy of behavioural approaches to obesity prevention and treatment through encouraging increased physical activity and reduced energy intake. Such research is usually conducted as randomized trials, where participants receiving

\footnotetext{
*Correspondence: I.waters1@uq.edu.au

${ }^{\dagger}$ Equal contributors

${ }^{1}$ Cancer Prevention Research Centre, School of Population Health, The University of Queensland, Herston, Brisbane, QLD 4006, Australia Full list of author information is available at the end of the article
}

an intervention are compared to a control group who receive no treatment or current best practice (usual care) $[5,6]$.

Unanticipated improvements in the behaviour of control group participants have been observed in intervention trials targeting an array of behaviours, including hazardous drinking [7], antiretroviral therapy adherence [8], physical activity [9], and chronic disease selfmanagement [10]. Such improvements may occur in response to undergoing baseline assessment; due to participants' awareness of being involved in an experimental trial; or due to the delivery of more intensive 'usual care' than would be encountered beyond the research context [11]. It is possible that control group improvements may also occur in behavioural weight loss intervention trials. Control group improvements have the potential to reduce or even nullify intervention effects through reducing statistical power to detect significant effects. Therefore, understanding when and why control group improvements occur has important implications for researchers, not 
only with respect to the interpretation of intervention effects, but also in relation to the design of future behavioural weight loss intervention trials.

Reviews of the behavioural weight loss intervention literature have alluded to the fact control group participants may lose weight through participating in an intervention trial [12]. However, there have been no systematic investigations specifically addressing weight change in control group participants in behavioural weight loss intervention trials. Nor has an attempt been made to quantify the amount of weight change that can be expected for participants not receiving the intervention; or to identify factors that are likely to predict a greater amount of weight change (particularly weight loss) among control group participants. The first objective of this study is to systematically review the behavioural weight loss intervention literature in order to describe the associations between control group weight change and specific trial and sample characteristics. The second objective is to conduct a meta-analysis to quantify the amount of weight change that occurs only in control groups, and a meta-regression analysis to relate the size of this effect to specific trial and sample characteristics. This meta-analysis will not compare intervention group effect sizes with control group effect sizes as the aim of this study is not to draw conclusions on the effectiveness of behavioural interventions in achieving weight loss, but to examine the amount of weight change that occurs solely due to (control group) participation in such trials.

\section{Methods}

\section{Criteria for inclusion}

Reports of randomised controlled trials or quasiexperimental trials evaluating behavioural weight loss interventions targeting adult participants, and that were published in English between 2005 and 2010 were potentially eligible for inclusion in this review. An extensive number of behavioural weight loss interventions have been published and the decision to limit the review to papers that were published within this time frame was guided by practical considerations.

Intervention trials were excluded from the review if the primary objective of the trial was not weight reduction; or if they implemented strategies other than behaviour change in order to achieve weight reduction (e.g., intervention components included pharmacological therapy, nutritional supplementation, herbal remedies or surgery). Trials were also excluded if they did not recruit a control or usual care group, or if participants allocated to the comparison condition received an alternative behavioural weight loss intervention or an attention control condition. Trials that did not report, or provide sufficient information to enable calculation of weight change (in kilograms) from baseline to follow up for each group were also excluded. Finally, trials recruiting participants who were pregnant or lactating, or had a medical condition which could confound the effect of a weight loss intervention (e.g., Prader Willi syndrome) were also excluded. No restriction was placed on the duration of trials; however, for trials that reported outcomes post-intervention and following a period of maintenance where no intervention was delivered, weight changes reported immediately following the intervention (not following the maintenance period) were used. This was done in order to standardise the definition of intervention duration for trials with and without a maintenance period.

\section{Electronic searches}

Electronic databases (Pub Med [1951], Web of Science [1981], EMBASE [1980], PsychINFO [1967]) were searched in December 2010 for reports of weight loss intervention trials using a combination of the following Medical Subject Headings (MeSH) and text words: (( obes* OR overweight OR weight gain* OR weight los* OR weight cycling OR weight reduc* OR weight maint*OR weight decreas* OR body mass index OR adipos* OR overload syndrom* OR weight watch* OR weight control*) AND (exercise* OR exercise-therapy OR physical education* OR physical fitness OR exertion* OR sport* OR walking OR jogging OR swimming OR bicyc* OR cycling OR weight lift* OR gymnastic* OR danc* OR strength train* OR resistance train*OR aerobic train* OR Lifestyle OR Health* educ* OR health* behav* OR health* promo$t^{*}$ OR nutrition* OR diet* OR diet therapy OR diabetic diet) AND (random* OR clinical trial OR control group OR meta analysis OR intervention OR random allocation OR intervention studies))).

\section{Study selection}

One person, LW, screened the titles and abstracts of articles identified through electronic database searches. Full text versions of reports of trials that appeared to be relevant to the review were retrieved and read in full. A checklist developed prior to the search, and based on the list of inclusion and exclusion criteria, was used to systematically identify papers for inclusion. A second person (AS) independently screened $15 \%$ of the articles (selected at random) and agreement between reviewers was $100 \%$.

\section{Data abstraction}

Data was abstracted and coded by two reviewers (LW and AS). The primary outcome variable was mean weight change in kilograms from baseline to post-intervention follow up. Where this variable was not reported, but the mean weight for each group at baseline and follow up 
was given, change was calculated. For trials that reported weight in pounds, a conversion to kilograms was undertaken. Information on characteristics that were hypothesised to be potentially associated with control group weight change was recorded, and categorised as being related to trial design, treatment of the control group, or characteristics of the enrolled participants.

\section{Trial design and methodology}

Weight loss interventions were evaluated using randomised controlled trials or quasi-experimental (nonrandomised controlled) trials. Participant recruitment strategies were categorised as being either an approach that involved identifying potential participants through searches of existing registers (e.g., general practice lists or existing trial cohorts) or appealing to volunteers through the media or by contacting existing community organisations (such as schools, workplaces or churches). Trial duration was defined as the length of time from baseline to immediate post-intervention follow up (excluding any period of maintenance). Sample size and the number of times a participant underwent assessment of body weight were also recorded.

\section{Control group treatment}

The description of the treatment delivered to the control group was categorised as being a "no intervention control" condition, "waiting list control" condition or "usual care". To be categorised as a no intervention control group, participants allocated to this group must have received no treatment other than undergoing assessments. Similarly, participants in a waiting list control group received no treatment during the trial, but were informed that they would have the opportunity to receive the intervention components following the completion of the study. Participants allocated to a usual care control group received the same level of treatment that a person would normally have received, or could have had access to, outside of the intervention context. Usual care treatment may have included the issue of standard print leaflets addressing topics related to diet or physical activity, brief education sessions addressing topics such as risk factors for chronic disease, or advice to maintain usual behaviour patterns.

\section{Characteristics of participants}

Information on participants' baseline characteristics, including age, gender, health status and body mass index, were abstracted and coded. The mean age of the sample in each trial was recorded, as was the proportions of female participants. Baseline health status was determined in the following way: participants in trials that specifically aimed to recruit people with an existing medical or psychiatric condition (e.g., cancer, diabetes, chronic heart disease, schizophrenia, obstructive sleep apnoea) were defined as having a chronic disease. In trials where recruitment was not targeted towards people with an existing medical condition, but where the mean BMI of the sample was in the overweight or obese range (BMI> $25 \mathrm{~kg} / \mathrm{m}^{2}$ ) [13], participants were categorised as being at risk of a chronic disease. For trials where the mean BMI of the sample was in the healthy weight range $(B M I \geq$ $18 \mathrm{~kg} / \mathrm{m}^{2}$ and $\leq 25 \mathrm{~kg} / \mathrm{m}^{2}$ ) and participants were free from existing medical and psychiatric conditions, participants were classified as being recruited from a healthy population.

\section{Data analysis}

\section{Bivariate analysis}

A simple, descriptive bivariate analysis was conducted to assess the associations between control group weight change in kilograms, and variables hypothesized to be potentially associated with control group change (PASW v.18; SPSS, Chicago, IL). The dependent variable (control group weight change) was not normally distributed; therefore non-parametric tests of association were employed (Mann-Whitney U test or Kruskal-Wallis test for categorical variables and Spearman rank correlation coefficients for continuous variables). Continuous variables (trial duration, number of assessments undertaken, mean age and BMI in each trial) were also transformed into categorical values according to the median value, or another logical value to avoid loss of statistical power in subsequent analyses as these variables were not normally distributed and the range of values were small and inconsistent across all studies.

\section{Meta-analysis and meta-regression}

The study protocol adhered to PRISMA guidelines for reporting systematic reviews and meta-analyses. The meta-analysis and meta-regression analysis were performed using STATA v.11 (StataCorp, 2009). Publication bias was investigated visually using a funnel plot and formally by Egger's and Begg's tests, using the user-written "meta" and "metabias" commands. The percentage of variation attributable to heterogeneity $\left(\mathrm{I}^{2}\right)$ was computed from Cochran Q statistic. Given the potential for heterogeneity in the studies reviewed, a random effects model was deemed to be most appropriate. The standard error (SE) of the primary outcome variable (weight change in kilograms) was extracted directly from published reports, or computed from the reported standard deviation (SD), 95\% confidence limits or exact p-value. For trials that did not report mean weight change, but reported mean group weight (and either SE or SD) at baseline and follow up, standard errors of weight change were calculated assuming an intra-correlation coefficient of $\rho=0.5$. $P$ values that were reported as $<0.01$ or $<0.0001$ 
were replaced by 0.005 and 0.00005 respectively. When the upper bound $<0.01$ and $<0.0001$ were not provided; we took the mid-point of 0.01 to 0.001 and 0.0001 to 0.00001 .

Meta regression ("metareg" command) was performed to investigate the association between weight change and trial and sample characteristics that were designated a priori. The characteristics under investigation were those included in the bivariate analysis, as well as trial sample size $(n \geq 100$ or $<100)$ and the method by which the SE of weight change was determined (reported or calculated based on SE/SD/exact p-values). Dichotomised categorical versions of continuous variables were used in the meta-regression analysis to prevent loss of statistical power. Uni-variable and multi-variable metaregression models were carried out. Results are presented as random effect coefficient estimates with 95\% confidence intervals (CI) and p-values.

\section{Results}

Following the removal of duplicates, the total number of references identified through electronic database searching was 1,467; of which 1,124 were intervention trials targeting weight loss. Reports of trials in which weight change was a secondary, and not primary, outcome were excluded $(n=239)$; as were studies that reported on the evaluation of the effectiveness of a surgical procedure, nutritional or herbal supplement, or pharmacological treatment $(n=330)$. Reports of trials without a control or usual care comparison group $(n=400)$, and where recruited participants were pregnant, lactating or had a medical condition that could influence their ability to lose weight $(n=50)$ were also excluded. The remaining 105 publications reported the outcomes from 93 individual behavioural weight loss intervention trials. A further 8 of these were excluded because weight change was reported in a metric other than kilograms or pounds (e.g., BMI). Therefore, eighty-five reports of intervention trials met the inclusion criteria for this review. Seventy-two of these reports provided either the SE of weight change for the control group, or sufficient information to allow for this to be calculated (SE/SD/exact p-value of control group weight at baseline and follow-up) and were therefore included in the meta-regression analysis (Figure 1). A full list of the intervention trials included in the review is provided in Additional file 1: Appendix 1.

\section{Description of studies included in the review Trial design and methodology}

Sample sizes for the 85 trials included in the review ranged from 15 [14] to 68,591 [15] with a median sample size of 81 participants. The majority of trials $(n=78$; 92\%) employed a randomized controlled trial design with the remaining seven (8\%) being quasi-experimental trials. Detailed accounts of the strategies used to recruit participants were provided in 76 reports $(89 \%)$, with over half of those trials $(n=49 ; 58 \%)$ recruiting participants through appeals to volunteers via the media or by contacting existing community organisations (such as schools, workplaces or churches). The remainder $(n=36$; $42 \%$ ) identified participants from existing registers (e.g., general practice lists or existing trial cohorts). The duration between baseline and post-intervention follow up spanned from six weeks [16] to four and a half years, [17] with the median duration being 6 months. Control group participants in all trials were assessed at baseline and follow up; and at least one additional assessment was conducted in almost one third of studies $(n=26$, $31 \%)$. In all but one trial [18], weight was measured objectively in a clinical setting.

\section{Control group treatment}

In 33 trials (39\%), participants were allocated to a no intervention control condition and received no treatment other than undergoing assessment. In a further 14 studies (16\%), participants in the control group were informed that they would receive the intervention at the completion of the trial (wait list control). Participants in the comparison group in the remaining 38 studies (44\%) received usual care. The content of the usual care treatment was not consistently described, but most often involved the receipt of standard off-the-shelf print material addressing health behaviours, but may have also included a single information session delivered in a group setting or individual consultation.

\section{Characteristics of participants}

The mean age of the study sample was reported for 81 trials and varied from 19.2 years [19] to 63.7 years [20]. For those 81 trials, the median of the distribution of sample ages was 48.7 years. In terms of the gender distribution within study samples, 24 trials $(28 \%)$ recruited only females, and a further 24 trials $(28 \%)$ recruited mostly females ( $\geq 60 \%$ female). In contrast, only seven trials (8\%) exclusively targeted male participants, while in a further eight trials (9\%) males formed more than $60 \%$ of the sample. Twenty-two trials $(26 \%)$ had a relatively even gender distribution (40-60\% female). Eightyone studies reported the mean BMI for the control group at baseline, and this value varied from $23.8 \mathrm{~kg} / \mathrm{m}^{2}$ [21] to $43.6 \mathrm{~kg} / \mathrm{m}^{2}$ [22]. The median of the distribution of BMIs of the control group samples was $31.1 \mathrm{~kg} / \mathrm{m}^{2}$. In three trials $(4 \%)$, the mean BMI for the control group was in the healthy weight range, while in the remainder of studies, the control group sample was either overweight $(n=27 ; 33 \%)$ or obese $(n=48,59 \%)$. Of the three studies where the mean BMI of the control group was in the healthy weight range, one targeted participants who 


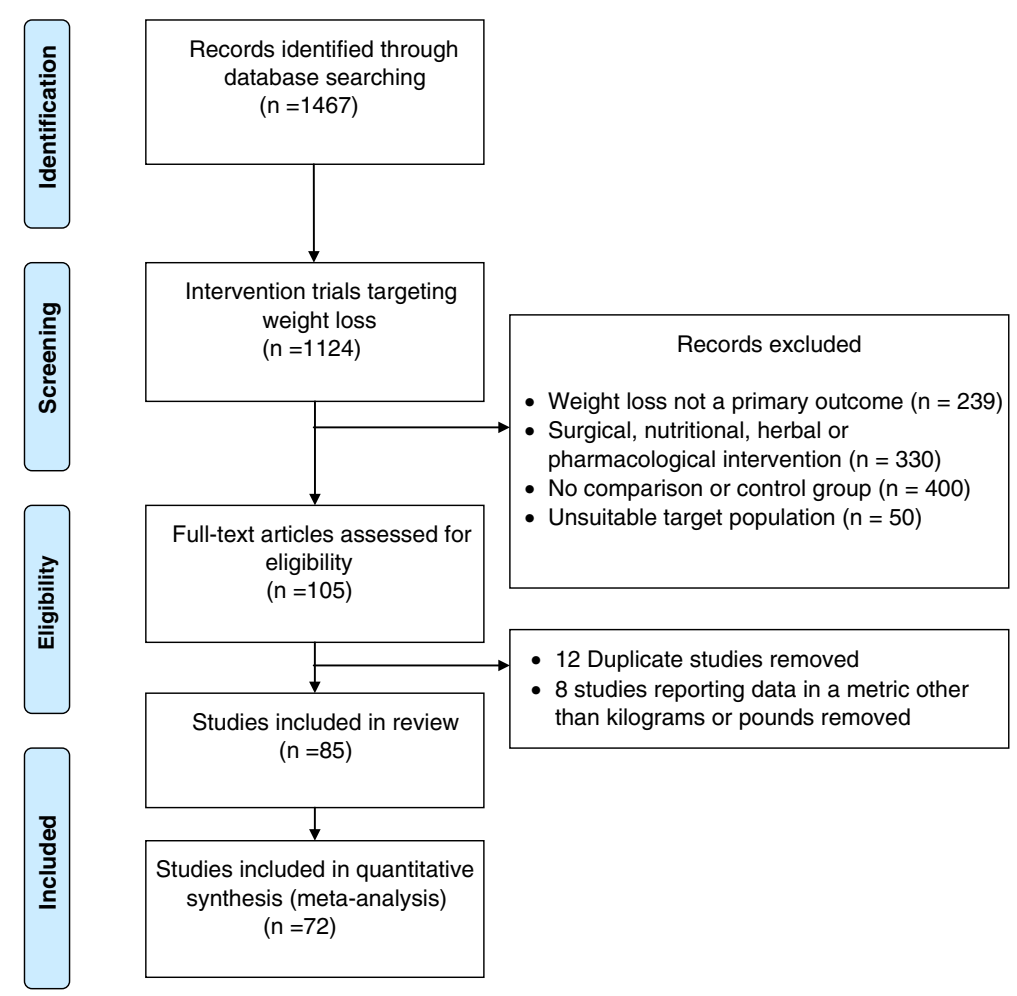

Figure 1 Flow diagram of studies included in the review.

were at high risk of gaining weight, one recruited East Asian males who met the criteria for overweight when ethnicity-specific cut-points were used and the remaining study was a family-based study. The majority of studies targeted participants who were at risk of a chronic disease through being overweight or obese, but who were otherwise healthy $(n=55,65 \%)$. Almost one third of studies $(n=26,31 \%)$ recruited participants who had been diagnosed with a chronic disease, and a small minority of studies $(n=4 ; 5 \%)$ targeted healthy populations.

\section{Bivariate analyses}

Across all 85 trials, the median weight change for control groups was negligible (median $=+0.1 \mathrm{~kg}$; IQR $=-0.85 \mathrm{~kg}$ to $+0.8 \mathrm{~kg}$ ), and ranged from a mean group weight loss of $5.8 \mathrm{~kg}$ [23] to a mean group weight gain of $4 \mathrm{~kg}$ [24]. Statistical analyses revealed no significant associations between control group weight change and the explanatory variables (Table 1). While the purpose of this review was not to quantify the amount of weight change in intervention groups, or to examine factors associated with greater weight loss among participants who received an intervention, analyses were repeated for the intervention groups for comparative purposes to demonstrate differences in the average weight change between intervention recipients and controls. The median weight loss for the intervention groups across all trials was $-2.7 \mathrm{~kg}$ $(\mathrm{IQR}=-5 \mathrm{~kg}$ to $-1.35 \mathrm{~kg}$; range: $-18.7 \mathrm{~kg}$ [25] to $+2.5 \mathrm{~kg}$ [26]).

\section{Meta-analysis and meta-regression}

A high level of heterogeneity was present $(\mathrm{Q}=847.1$; $\mathrm{df}=$ $71 ; \mathrm{p}=0.000)$ with the $\mathrm{I}^{2}$ statistic indicating that $92 \%$ of the variation in control group weight change was attributable to heterogeneity in the studies reviewed. The results from the meta-analysis confirmed the findings of the bivariate analysis. The random effect combined weight change for the control group was $-0.1 \mathrm{~kg}$ (95\%CI: -0.4 , 0.1 ) and not statistically significantly different from zero (Figure 2).

In the uni-variable meta-regression model, three variables were found to be significant predictors of control group weight change (Table 2). The meta-regression coefficient for weight change was significantly lower in trials with a usual care group compared to those with a no intervention control group $(-0.84 \mathrm{~kg}$; CI:-1.55, -0.13; $\mathrm{p}=0.021)$; in randomised controlled trials compared to quasi-experimental trials $(-1.11 \mathrm{~kg}$; CI: $-2.17,-0.06 ; \mathrm{p}=$ 0.038 ) and in trials where the SE of weight change was derived from the $\mathrm{SE} / \mathrm{SD} /$ exact $\mathrm{p}$-value $(-1.02 \mathrm{~kg}$; $\mathrm{CI}$ : $-2.00,-0.03 ; \mathrm{p}=0.043)$ as opposed to other methods. In the multi-variable regression model, the only significant 
Table 1 Bivariate associations between explanatory variables and control group weight change (kg)

\begin{tabular}{|c|c|c|c|c|}
\hline \multirow{2}{*}{$\begin{array}{l}\text { Trial and participant characteristics: } \\
\text { Trial Characteristics }\end{array}$} & \multirow[t]{2}{*}{ Study $\mathbf{n}$} & \multicolumn{2}{|c|}{ Median group weight change (Inter-quartile range) } & \multirow[t]{2}{*}{ p-value } \\
\hline & & & & \\
\hline \multicolumn{5}{|l|}{ Trial design } \\
\hline Randomised controlled trial & 78 & 0.0 & $(-1.1,0.8)$ & \\
\hline Quasi-experimental study design & 7 & 0.5 & $(-0.2,0.9)$ & 0.200 \\
\hline \multicolumn{5}{|l|}{ Recruitment strategy } \\
\hline Searches of existing registers & 36 & 0.4 & $(-0.8,1.25)$ & \\
\hline Media appeal for volunteers & 40 & 0.0 & $(-1.1,0.6)$ & 0.498 \\
\hline \multicolumn{5}{|l|}{ Intervention duration ${ }^{* \delta}$} \\
\hline$\leq 6$ months & 54 & 0.1 & $(-0.8,0.6)$ & \\
\hline$>6$ months & 31 & 0.2 & $(-1.1,1.9)$ & 0.637 \\
\hline \multicolumn{5}{|l|}{ Total number of assessments* } \\
\hline 2 (baseline and follow up) & 59 & 0.2 & $(-0.5,0.7)$ & \\
\hline$>2$ (at least one interim assessment) & 26 & -0.6 & $(-1.4,1.3)$ & 0.468 \\
\hline \multicolumn{5}{|l|}{ Control group treatment } \\
\hline No intervention control group & 33 & 0.3 & $(-0.4,0.6)$ & \\
\hline Wait list control group & 14 & 0.4 & $(-0.4,2.1)$ & \\
\hline Usual care group & 38 & -0.5 & $(-1.3,0.8)$ & 0.139 \\
\hline \multicolumn{5}{|l|}{ Sample Characteristics } \\
\hline \multicolumn{5}{|l|}{ Age $^{*}$} \\
\hline$\leq 50$ years & 45 & 0.4 & $(-1.1,0.9)$ & \\
\hline$>50$ years & 36 & 0.0 & $(-0.7,0.8)$ & 0.427 \\
\hline \multicolumn{5}{|l|}{ Gender } \\
\hline Mostly female (>60 \% female) & 48 & -0.1 & $(-1.1,0.8)$ & \\
\hline Mixed gender or mostly male & 37 & 0.3 & $(-0.8,1.0)$ & 0.346 \\
\hline \multicolumn{5}{|l|}{ Target population } \\
\hline Healthy or at risk of chronic disease & 59 & 0.0 & $(-1.1,0.6)$ & \\
\hline Chronic disease & 26 & 0.3 & $(-0.8,1.2)$ & 0.247 \\
\hline \multicolumn{5}{|l|}{ Baseline mean BMI category } \\
\hline Healthy or overweight $\left(\geq 18-<25 \mathrm{~kg} / \mathrm{m}^{2}\right)$ & 33 & 0.3 & $(-0.5,0.8)$ & \\
\hline Obese (> 30 kg/m2) & 48 & 0.0 & $(-1.1,0.9)$ & 0.441 \\
\hline
\end{tabular}

*Dichotomised based on the median value.

${ }^{\delta}$ When analysed as a continuous variable, there was no difference in trial duration for studies that had a mean control group weight loss and those that had a mean control group weight gain.

predictor of control group weight change was control group treatment with trials with a usual care group having a significantly lower meta-regression coefficient for weight change than trials with a no intervention control group (-1.23 kg; CI: $-2.22,-0.23 ; \mathrm{p}=0.016)$ (Table 2).

In comparison, the random effect combined weight change for the intervention group was $-3.36 \mathrm{~kg}$ (95\% CI:-3.89, -2.82), and significantly different from zero. In the uni-variable model, the meta-regression coefficient for weight change was significantly higher in trials with a sample size $\geq 100$ (1.95 kg; CI: $0.07,3.82 ; \mathrm{p}=0.042)$, but none of the explanatory variables were significant predictors of intervention group weight change in the multi-variable model (Table 2).

\section{Discussion}

This research is novel in providing an understanding of changes in the behaviour of control groups, rather than intervention groups. This is the first review to investigate weight change occurring in control groups in behavioural weight loss intervention trials, and whether certain trial or sample characteristics might predict greater control group weight change. The overall weight change in control groups was not significantly different from zero; however, there is some evidence that providing usual care to control groups may have a greater effect on weight loss than if no treatment were provided. Control groups receiving usual care lost significantly more weight than no intervention control groups 


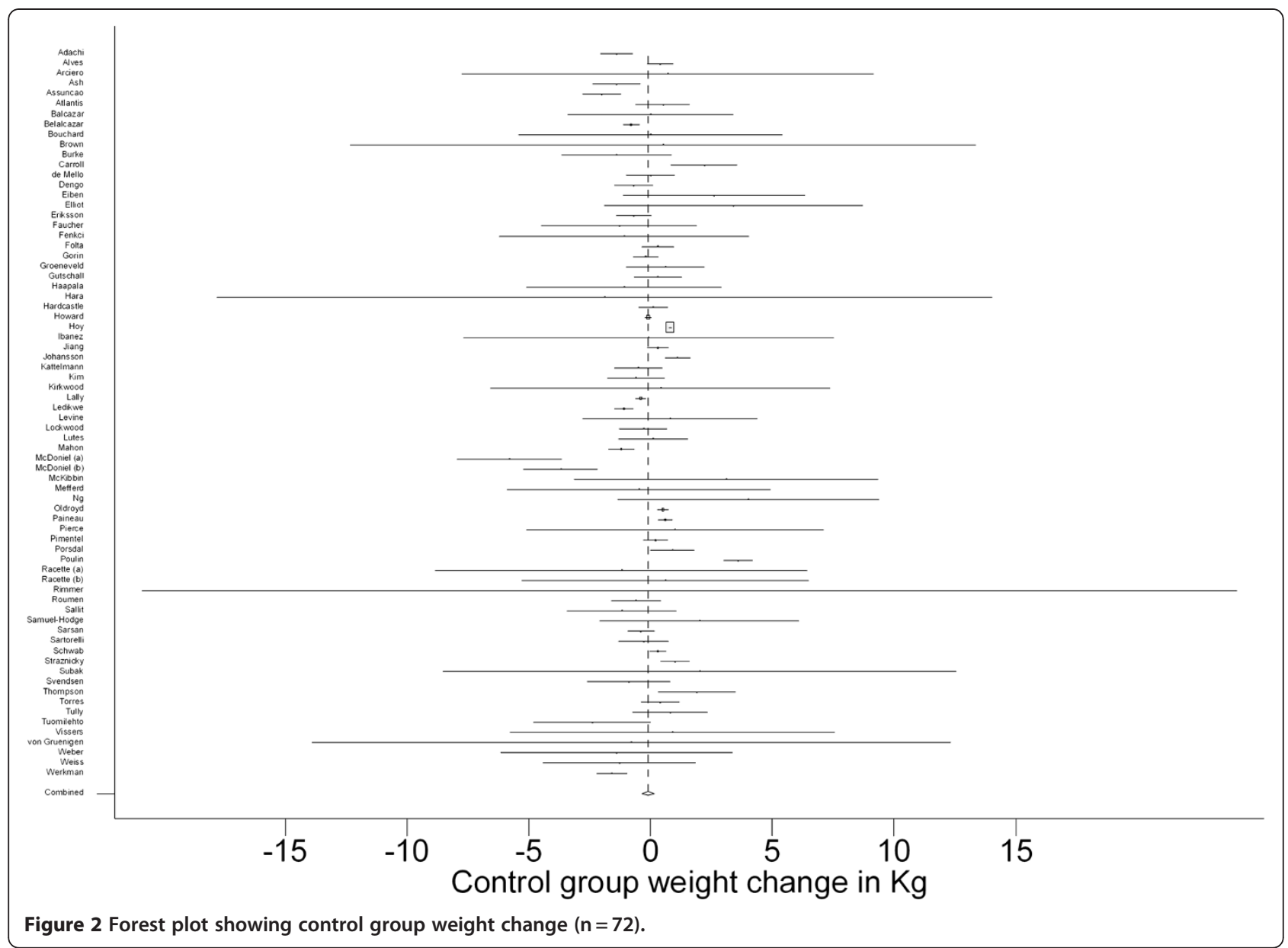

(1.23 kg weight loss compared to no weight change respectively).

Favourable behaviour changes among control group participants have been observed for a diverse range of other health behaviours [7-9]. The fact that these findings were not replicated in the sample of weight loss intervention trials reviewed is an interesting finding. There are several plausible explanations for why control group improvements may be observed in intervention trials targeting other behaviours, but not those that aim to change participants' body weight through employing behaviour change strategies.

Behavioural weight loss intervention trials are distinct from those targeting other behaviours in that the primary outcome is most often physical (i.e., change in body weight) rather than behavioural (i.e., change in diet or physical activity). Furthermore, body weight is objectively assessed using calibrated scales, as it was in all but one of the intervention trials reviewed. In contrast, while objective measures are available for measuring physical activity and alcohol consumption (two behaviours for which control group improvements in intervention trials have been reported), there is a greater reliance on self- report measures of behaviour change [7,9]. Self-report measures are susceptible to social desirability bias [27] and it may be that self-reported behaviour changes in control groups reflect unreliable reporting rather than actual behaviour changes. Alternatively, it may be that control group participants in behavioural weight loss intervention trials do change their behaviour, but not sufficient to induce actual weight loss.

Given multiple, inter-related biologic, genetic, social, and cultural influences, it is difficult to induce behaviour changes that lead to sustained weight loss $[28,29]$. Thus, it is possible that the lack of control group weight loss observed in this review reflects both the complexity and difficulty in achieving weight loss through behavioural strategies alone [12]. Control group changes may be more likely in intervention trials targeting less complex behaviours. For example, control group changes in behavior and objectively measured clinical outcomes have been seen in intervention trials targeting antiretroviral medication adherence $[8,30]$. The evidence in this field of research indicates an association between the quality of usual care treatment and control group outcomes [30]. 
Table 2 Random effects meta-regression analysis, association of explanatory variables with control group weight change $\mathbf{( k g )}$

\begin{tabular}{|c|c|c|c|c|c|c|c|}
\hline \multirow[b]{2}{*}{ Trial and participant characteristics: } & \multirow[b]{2}{*}{$\begin{array}{c}\text { Study } \\
\text { n }\end{array}$} & \multicolumn{3}{|c|}{ Uni-variable } & \multicolumn{3}{|c|}{ Multi-variable } \\
\hline & & \multicolumn{2}{|c|}{$\begin{array}{c}\text { Weight change } \\
\text { coefficient }(95 \% \mathrm{Cl})\end{array}$} & \multirow[t]{2}{*}{ p-value } & \multicolumn{2}{|c|}{$\begin{array}{c}\text { Weight change } \\
\text { coefficient }(95 \% \mathrm{Cl})\end{array}$} & \multirow[t]{2}{*}{$\mathrm{p}$-value } \\
\hline Method of ascertaining SE of weight change & & & & & & & \\
\hline Reported $(r e f=0)$ & 23 & & & & & & \\
\hline From SE/SD/exact $p$ & 49 & -1.02 & $(-2.00,-0.03)$ & 0.043 & -0.82 & $(-1.85,0.21)$ & 0.119 \\
\hline \multicolumn{8}{|l|}{ Sample size } \\
\hline$<100($ ref = 0$)$ & 61 & & & & & & \\
\hline$\geq 100$ & 11 & -0.01 & $(-0.85,0.83)$ & 0.976 & 0.68 & $(-0.32,1.68)$ & 0.181 \\
\hline \multicolumn{8}{|l|}{ Trial design } \\
\hline Quasi-experimental $(r e f=0)$ & 6 & & & & & & \\
\hline RCT & 66 & -1.11 & $(-2.17,-0.06)$ & 0.038 & -0.37 & $(-1.56,0.81)$ & 0.538 \\
\hline \multicolumn{8}{|l|}{ Recruitment strategy } \\
\hline Media appeal for volunteers $(r e f=0)$ & 43 & & & & & & \\
\hline Searches of existing registers & 29 & -0.03 & $(-0.71,0.66)$ & 0.937 & -0.13 & $(-0.62,0.88)$ & 0.732 \\
\hline \multicolumn{8}{|l|}{ Intervention duration } \\
\hline$\leq 6$ months $(r e f=0)$ & 47 & & & & & & \\
\hline$>6$ months & 25 & 0.29 & $(-0.41,1.00)$ & 0.412 & 0.72 & $(-0.17,1.61)$ & 0.113 \\
\hline \multicolumn{8}{|l|}{ Total number of assessments } \\
\hline 2 & 52 & & & & & & \\
\hline$>2(r e f=0)$ & 20 & -0.47 & $(-1.24,0.30)$ & 0.234 & -0.27 & $(-1.06,0.51)$ & 0.492 \\
\hline \multicolumn{8}{|l|}{ Control group treatment } \\
\hline No intervention control group $(r e f=0)$ & 26 & & & & & & \\
\hline Wait list control group & 13 & 0.26 & $(-0.65,1.16)$ & 0.579 & 0.85 & $(-0.10,1.80)$ & 0.079 \\
\hline Usual care group & 33 & -0.84 & $(-1.55,-0.13)$ & 0.021 & -1.23 & $(-2.22,-0.23)$ & 0.016 \\
\hline \multicolumn{8}{|l|}{ Age } \\
\hline$\leq 50$ years $($ ref $=0)$ & 34 & & & & & & \\
\hline$>50$ years & 35 & -0.01 & $(-0.71,0.69)$ & 0.971 & -0.32 & $(-1.07,0.43)$ & 0.406 \\
\hline \multicolumn{8}{|l|}{ Gender } \\
\hline Mixed gender or mostly male $(r e f=0)$ & 33 & & & & & & \\
\hline Mostly female (>60 \% female) & 39 & -0.22 & $(-0.90,0.45)$ & 0.517 & 0.14 & $(-0.56,0.84)$ & 0.695 \\
\hline \multicolumn{8}{|l|}{ Target population } \\
\hline Chronic disease $(r e f=0)$ & 23 & & & & & & \\
\hline Healthy or at risk of chronic disease & 49 & -0.38 & $(-1.09,0.32)$ & 0.286 & -0.49 & $(-1.26,0.29)$ & 0.216 \\
\hline \multicolumn{8}{|l|}{ Baseline BMI category } \\
\hline Healthy or overweight $(\leq 30 \mathrm{~kg} / \mathrm{m} 2)(\mathrm{ref}=0)$ & 26 & & & & & & \\
\hline Obese (> 30 kg/m2) & 43 & -0.24 & $(-0.96,0.48)$ & 0.513 & -0.24 & $(-0.95,0.47)$ & 0.501 \\
\hline
\end{tabular}

While the findings of this review appear to suggest that neither the treatment of the control group, nor the application of procedures associated with administering an intervention trial (e.g., measurement, recruitment strategies) appear sufficient to significantly change participants' body weight, it is possible that control group participation confers benefits through the prevention of weight gain. Interventions aimed at preventing weight gain in healthy populations have become the focus of research attention in recent years [31,32]. Prospective studies show that there is a tendency towards weight gain over time [33,34]. Although the time period considered in the studies reviewed was likely to be too short to detect control group weight gain, if weight gain prevention occurred, there would be implications for the development of minimal intensity weight gain prevention interventions. Further research dedicated to understanding which elements of the control group assessment 
might be useful for weight gain prevention (research procedures, the content of usual care, or the interaction between the two) is warranted.

This review has a number of limitations. First, the results of the meta-analysis must be interpreted with caution, given the extent of heterogeneity observed. This review was limited to intervention trials published between 2005 and 2010. The decision to limit the review to papers published within this timeframe was made for practical purposes as the literature addressing behavioural weight loss interventions is vast. It is possible that the results of this study may have been impacted by the decision to limit the review to this timeframe. It is also not possible to exclude publication bias given the reliance on published manuscripts. A large number of explanatory variables were included in the meta-regression model, potentially increasing the probability of false positive conclusions. However, this is unlikely to have been a problem, given that very few of the explanatory variables were significantly associated with the outcome variable. A more parsimonious model containing a fewer explanatory variables yielded similar results. The usual care treatment delivered to participants in the control group was often not described comprehensively, precluding analysis of the effects of the content of usual care treatment on control group outcomes. The absence of sufficient information to enable replication of the usual care condition has been noted in previous studies and is a barrier to understanding control group improvements $[8,30,35]$. However, given the overall null findings related to weight change, the utility of such an analysis would be questionable in the context of this review.

\section{Conclusions}

Contrary to other areas of behaviour change research where control group improvements have been observed [7-9], in behavioural weight loss interventions control groups mostly showed negligible changes in weight status. The findings of this review suggest that it is difficult to achieve weight loss, and exposure to measurement alone is insufficient to initiate measureable behaviour change. Minimal intensity interventions may have a role in a range of health behaviours but appear not to do so with respect to weight loss.

\section{Additional file}

Additional file 1: Appendix. Description of intervention trials included in "Weight change in the control group participants in behavioural weight loss interventions: A systematic review and meta-regression study [14-26,36-107].

\section{Competing interests}

The authors declare that they have no competing interests.

\section{Authors' contributions}

All four authors contributed to the conception and design of the study. LW carried out the literature search. LW and ASG reviewed articles for inclusion in the review and abstracted data. LW conducted the descriptive data analysis and TC completed the meta-regression analysis. All authors helped to draft the manuscript and all authors read and approved the final manuscript.

\section{Acknowledgements}

LW is supported by a National Heart Foundation scholarship.

\section{Author details}

${ }^{1}$ Cancer Prevention Research Centre, School of Population Health, The University of Queensland, Herston, Brisbane, QLD 4006, Australia. ${ }^{2}$ Prevention Research Collaboration, School of Public Health, The University of Sydney, Sydney, NSW 2006, Australia.

Received: 7 November 2011 Accepted: 23 July 2012

Published: 8 August 2012

\section{References}

1. Obesity: Preventing and managing the global epidemic Report of a WHO consultation. Geneva; 2000. Technical Report Series, 894, i-xii, 1-253.

2. Haslam D, James W: Obesity. Lancet 2005, 366:1197-1209.

3. Global strategy on diet, physical activity and health. World Health Organisation; 2004.

4. US Department of Health and Human Services: The Surgeon General's call to action to prevent and decrease overweight and obesity. Washington: 2001.

5. Schmitz MK, Jeffery RW: Public health interventions for the prevention and treatment of obesity. Med Clin North Am 2000, 84:491-512. viii.

6. Sharma M: Behavioural interventions for preventing and treating obesity in adults. Obesity Rev 2007, 8:441-449.

7. Jenkins RJ, McAlaney J, McCambridge J: Change over time in alcohol consumption in control groups in brief intervention studies: systematic review and meta-regression study. Drug Alcohol Depend 2009, 100:107-114.

8. de Bruin M, Viechtbauer W, Schaalma HP, Kok G, Abraham C, Hospers HJ: Standard Care Impact on Effects of Highly Active Antiretroviral Therapy Adherence Interventions: A Meta-analysis of Randomized Controlled Trials. Arch Intern Med 2010, 170:240-250.

9. Waters L, Reeves M, Fjeldsoe B, Eakin E: Control group improvements in physical activity intervention trials and possible explanatory factors: A systematic review. J Phys Act Healt, in press.

10. Becker H, Roberts $G$, Voelmeck W: Explanations for improvement in both experimental and control groups. West J Nurs Res 2003, 25:746.

11. Eakin E, Reeves M, Lawler S, Graves N, Oldenburg B, Del Mar C, Wilke K, Winkler E, Barnett A: Telephone counseling for physical activity and diet in primary care patients. Am J Prev Med 2009, 36:142-149.

12. McTigue KM, Harris R, Hemphill B, Lux L, Sutton S, Bunton AJ, Lohr KN: Screening and interventions for obesity in adults: summary of the evidence for the U.S. Preventive Services Task Force. Ann Intern Med 2003, 139:933-949.

13. Global Database on Body Mass Index: World Health Organization; http://who.int/bmi/index.jsp.

14. Weber $M$, Wyne $K$ : A cognitive/behavioral group intervention for weight loss in patients treated with atypical antipsychotics. Schizophrenia Res 2006, 83:95-101.

15. Robbins AS, Chao SY, Baumgartner N, Runyan CN, Oordt MS, Fonseca VP: A low-intensity intervention to prevent annual weight gain in active duty Air Force members. Military Med 2006, 171:556-561.

16. Merrill RM, Massey MT, Aldana SG, Greenlaw RL, Diehl HA, Salberg A: C-reactive protein levels according to physical activity and body weight for participants in the coronary health improvement project. Prev Med 2008, 46:425-430.

17. Park HA, Lee JS, Kuller LH, Cauley JA: Effects of weight control during the menopausal transition on bone mineral density. J Clin Endocrinol Metab 2007, 92:3809-3815.

18. Sallit J, Ciccazzo M, Dixon Z: A cognitive-behavioral weight control program improves eating and smoking behaviors in weight-concerned female smokers. J Am Diet Assoc 2009, 109:1398-1405. 
19. Hara T, Fujiwara H, Nakao H, Mimura T, Yoshikawa T, Fujimoto S: Body composition is related to increase in plasma adiponectin levels rather than training in young obese men. Eur J Appl Physiol 2005, 94:520-526.

20. Dengo AL, Dennis EA, Orr JS, Marinik EL, Ehrlich E, Davy BM, Davy KP: Arterial destiffening with weight loss in overweight and obese middle-aged and older adults. Hypertension 2010, 55:855-861.

21. Kosaka K, Noda M, Kuzuya T: Prevention of type 2 diabetes by lifestyle intervention: a Japanese trial in IGT males. Diabetes Res Clin Pract 2005, 67:152-162.

22. Rimmer JH, Rauworth A, Wang E, Heckerling PS, Gerber BS: A randomized controlled trial to increase physical activity and reduce obesity in a predominantly African American group of women with mobility disabilities and severe obesity. Prev Med 2009, 48:473-479.

23. McDoniel SO, Hammond RS: A 24-week randomised controlled trial comparing usual care and metabolic-based diet plans in obese adults. Int J Clin Pract 2010, 64:1503-1511.

24. Ng TW, Chan DC, Barrett PH, Watts GF: Effect of weight loss on HDL-apoA-II kinetics in the metabolic syndrome. Clin Sci 2009, 118:79-85.

25. Johansson K, Neovius M, Lagerros YT, Harlid R, Rossner S, Granath F, Hemmingsson E: Effect of a very low energy diet on moderate and severe obstructive sleep apnoea in obese men: a randomised controlled trial. BMJ 2009, 339:b4609.

26. Pimentel GD, Portero-McLellan KC, Oliveira EP, Spada AP, Oshiiwa M Zemdegs JC, Barbalho SM: Long-term nutrition education reduces several risk factors for type 2 diabetes mellitus in Brazilians with impaired glucose tolerance. Nutr Res 2010, 30:186-190.

27. Johnson TP, O'Rourke DP, Burris JE, Warnecke RB: An investigation of the effects of social desirability on the validity of self-reports of cancer screening behaviors. Med Care 2005, 43:565-573.

28. Shepherd R: Resistance to changes in diet. Proc Nutr Soc 2002, 61:267-272.

29. Leventhal $\mathrm{H}$ : Changing attitudes and habits to reduce risk factors in chronic disease. Am J Cardiol 1973, 31:571-580.

30. de Bruin M, Viechtbauer W, Hospers HJ, Schaalma HP, Kok G: Standard care quality determines treatment outcomes in control groups of HAART-adherence intervention studies: implications for the interpretation and comparison of intervention effects. Health Psych 2009, 28:668-674.

31. Lemmens VE, Oenema A, Klepp KI, Henriksen HB, Brug J: A systematic review of the evidence regarding efficacy of obesity prevention interventions among adults. Obesity Rev 2008, 9:446-455.

32. Kremers $S$, Reubsaet A, Martens M, Gerards S, Jonkers R, Candel M, de Weerdt I, de Vries N: Systematic prevention of overweight and obesity in adults: a qualitative and quantitative literature analysis. Obesity Rev 2009, 11:371-379.

33. Koh-Banerjee P, Chu NF, Spiegelman D, Rosner B, Colditz G, Willett W, Rimm E: Prospective study of the association of changes in dietary intake, physical activity, alcohol consumption, and smoking with 9-y gain in waist circumference among 16587 US men. Am J Clin Nutr 2003, 78:719-727

34. Brown WJ: Trends and changes in physical activity and weight data from the Australian Longitudinal Study of Women's Health [Internet]. Rotorua, New Zealand: NgahuruNational Nutrition and Physical Activity Public Health Conference; 2007. Available from: http://www.alswh.org.au/AbstractConf. php?qs ID $=450$.

35. Davidson K, Goldstein M, Kaplan R, Kaufmann P, Knatterud G, Orleans C, Spring B, Trudeau K, Whitlock E: Evidence-based behavioral medicine: What is it and how do we achieve it? Ann Behav Med 2003, 26:161-171.

36. Adachi $Y$, Sato $C$, Yamatsu K, Ito $S$, Adachi $K$, Yamagami T: A randomized controlled trial on the long-term effects of a 1-month behavioral weight control program assisted by computer tailored advice. Behavior Research and Therapy 2007, 45:459-470.

37. Alves JG, Gale CR, Mutrie N, Correia JB, Batty GD: A 6-Month exercise intervention among inactive and overweight Favela-residing women in Brazil: The Caranguejo Exercise Trial. Am J Pub Health 2009, 99:76-80.

38. Arciero PJ, Gentile CL, Martin-Pressman R, Ormsbee MJ, Everett M, Zwicky L, Steele CA: Increased dietary protein and combined high intensity aerobic and resistance exercise improves body fat distribution and cardiovascular risk factors. Int J Sport Nutr Exerc Metab 2006, 16:373-392.

39. Ash S, Reeves M, Bauer J, Dover T, Vivanti A, Leong C, Sullivan TO, Capra S: A randomised control trial comparing lifestyle groups, individual counselling and written information in the management of weight and health outcomes over 12 months. Int J Obesity 2006, 30:1557-1564.
40. Assuncao MCF, Gigante DP, Cardoso MA, Sartorelli DS, Santos IS: Randomized, controlled trial promotes physical activity and reduces consumption of sweets and sodium among overweight and obese adults. Nutr Res 2010, 30:541-549.

41. Atlantis E, Chow CM, Kirby A: Fiatarone Singh MA: Worksite intervention effects on physical health: a randomized controlled trial. Health Prom Int 2006, 21:191-200.

42. Azadbakht L, Mirmiran P, Esmaillzadeh A, Azizi T, Azizi F: Beneficial effects of a dietary approaches to stop hypertension eating plan on features of the metabolic syndrome. Diabetes Care 2005, 28:2823-2831.

43. Balcazar HG, de Heer H, Rosenthal L, Aguirre M, Flores L, Puentes FA, Cardenas VM, Duarte MO, Ortiz M, Schulz LO: A promotores de salud intervention to reduce cardiovascular disease risk in a high-risk Hispanic border population, 2005-2008. Prev Chron Dis 2010, 7:A28.

44. Belalcazar LM, Reboussin DM, Haffner SM, Hoogeveen RC, Kriska AM, Schwenke DC, Tracy RP, Pi-Sunyer FX, Ballantyne CM, Look ARG: A 1-Year lifestyle intervention for weight loss in individuals with type 2 diabetes reduces high C-reactive protein levels and identifies metabolic predictors of change. Diabetes Care 2010, 33:2297-2303.

45. Bouchard DR, Soucy L, Senechal M, Dionne IJ, Brochu M: Impact of resistance training with or without caloric restriction on physical capacity in obese older women. Menopause 2009, 16:66-72.

46. Brown C, Goetz J, Van Sciver A, Sullivan D, Hamera E: A psychiatric rehabilitation approach to weight loss. Psychiatr Rehabil J 2006, 29:267-273

47. Burke V, Beilin LJ, Cutt HE, Mansour J, Wilson A, Mori TA: Effects of a lifestyle programme on ambulatory blood pressure and drug dosage in treated hypertensive patients: a randomized controlled trial. J Hypertension 2005, 23:1241-1249.

48. Carroll S, Borkoles E, Polman R: Short-term effects of a non-dieting lifestyle intervention program on weight management, fitness, metabolic risk, and psychological wellbeing in obese premenopausal females with the metabolic syndrome. App Physiol Nutr \& Metab 2007, 32:125-142.

49. de Mello VD, Kolehmainen M, Schwab U, Mager U, Laaksonen DE, Pulkkinen L, Niskanen L, Gylling H, Atalay M, Rauramaa R, Uusitupa M: Effect of weight loss on cytokine messenger RNA expression in peripheral blood mononuclear cells of obese subjects with the metabolic syndrome. Metabolism 2008, 57:192-199.

50. Eiben $\mathrm{G}$, Lissner L: Health Hunters - An intervention to prevent overweight and obesity in young high-risk women. Int J Obesity 2006, 30:691-696

51. Elliot DL, Goldberg L, Kuehl KS, Moe EL, Breger RK, Pickering MA: The PHLAME (Promoting Healthy Lifestyles: Alternative Models' Effects) firefighter study: outcomes of two models of behavior change. J Occup Environ Med 2007, 49:204-213.

52. Eriksson KM, Westborg CJ, Eliasson MC: A randomized trial of lifestyle intervention in primary healthcare for the modification of cardiovascular risk factors. Scand J Pub Health 2006, 34:453-461.

53. Faucher MA, Mobley J: A community intervention on portion control aimed at weight loss in low-income Mexican American women. J Midwifery Womens Health 2010, 55:60-64.

54. Fenkci S, Sarsan A, Rota S, Ardic F: Effects of resistance or aerobic exercises on metabolic parameters in obese women who are not on a diet. Adv Ther 2006, 23:404-413.

55. Folta SC, Lichtenstein AH, Seguin RA, Goldberg JP, Kuder JF, Nelson ME: The StrongWomen-Healthy Hearts program: reducing cardiovascular disease risk factors in rural sedentary, overweight, and obese midlife and older women. Am J Pub Health 2009, 99:1271-1277.

56. Ghroubi S, Elleuch H, Chikh T, Kaffel N, Abid M, Elleuch MH: Physical training combined with dietary measures in the treatment of adult obesity. A comparison of two protocols. Ann Phys Rehabil Med 2009, 52:394-413.

57. Gorin AA, Wing RR, Fava JL, Jakicic JM, Jeffery R, West DS, Brelje K, Dilillo VG, Look AHERG: Weight loss treatment influences untreated spouses and the home environment: evidence of a ripple effect. Int J Obesity 2008, 32:1678-1684

58. Groeneveld IF, Proper KI, van der Beek AJ, van Mechelen W: Sustained body weight reduction by an individual-based lifestyle intervention for workers in the construction industry at risk for cardiovascular disease: Results of a randomized controlled trial. Prev Med 2010, 51:240-246. 
59. Gutschall MD, Miller CK, Mitchell DC, Lawrence FR: A randomized behavioural trial targeting glycaemic index improves dietary, weight and metabolic outcomes in patients with type 2 diabetes. Pub Health Nutr 2009, 12:1846-1854.

60. Haapala I, Barengo NC, Biggs S, Surakka L, Manninen P: Weight loss by mobile phone: a 1-year effectiveness study. Pub Health Nutr 2009, 12:2382-2391.

61. Hardcastle S, Taylor A, Bailey M, Castle R: A randomised controlled trial on the effectiveness of a primary health care based counselling intervention on physical activity, diet and CHD risk factors. Patient EduC Couns 2008, 70:31-39.

62. Howard BV, Manson JE, Stefanick ML, Beresford SA, Frank G, Jones B, Rodabough RJ, Snetselaar L, Thomson C, Tinker L, et al: Low-fat dietary pattern and weight change over 7 years: the Women's Health Initiative Dietary Modification Trial. JAMA 2006, 295:39-49.

63. Hoy MK, Winters BL, Chlebowski RT, Papoutsakis C, Shapiro A, Lubin MP, Thomson CA, Grosvenor MB, Copeland T, Falk E, et al: Implementing a low-fat eating plan in the Women's Intervention Nutrition Study. J Am Diet Assoc 2009, 109:688-696.

64. Ibanez J, Izquierdo M, Martinez-Labari C, Ortega F, Grijalba A, Forga L, Idoate F, Garcia-Unciti M, Fernandez-Real JM, Gorostiaga EM: Resistance training improves cardiovascular risk factors in obese women despite a significative decrease in serum adiponectin levels. Obesity 2009, 18:535-541.

65. Jiang $X$, Sit JW, Wong TK: A nurse-led cardiac rehabilitation programme improves health behaviours and cardiac physiological risk parameters: evidence from Chengdu, China. J Clin Nursing 2007, 16:1886-1897.

66. Kattelmann KK, Conti K, Ren C: The medicine wheel nutrition intervention: a diabetes education study with the Cheyenne River Sioux Tribe. J Am Diet Assoc 2009, 109:1532-1539.

67. Kim KH, Linnan L, Campbell MK, Brooks C, Koenig HG, Wiesen C: The WORD (wholeness, oneness, righteousness, deliverance): a faith-based weight-loss program utilizing a community-based participatory research approach. Health Educ Behav 2008, 35:634-650.

68. Kirkwood L, Aldujaili E, Drummond S: Effects of advice on dietary intake and/or physical activity on body composition, blood lipids and insulin resistance following a low-fat, sucrose-containing, high-carbohydrate, energy-restricted diet. Int J Food Sci Nutr 2007, 58:383-397.

69. Lally P, Chipperfield A, Wardle J: Healthy habits: efficacy of simple advice on weight control based on a habit-formation model. Int J Obesity 2008, 32:700-707.

70. Ledikwe JH, Rolls BJ, Smiciklas-Wright H, Mitchell DC, Ard JD, Champagne C, Karanja N, Lin PH, Stevens VJ, Appel LJ: Reductions in dietary energy density are associated with weight loss in overweight and obese participants in the PREMIER trial. Am J Clin Nutr 2007, 85:1212-1221.

71. Levine MD, Klem ML, Kalarchian MA, Wing RR, Weissfeld L, Qin L, Marcus MD: Weight gain prevention among women. Obesity 2007, 15:1267-1277.

72. Lockwood CM, Moon JR, Tobkin SE, Walter AA, Smith AE, Dalbo VJ, Cramer JT, Stout JR: Minimal nutrition intervention with high-protein/low-carbohydrate and low-fat, nutrient-dense food supplement improves body composition and exercise benefits in overweight adults: a randomized controlled trial. Nutr \& Metab 2008, 5. doi:10.1186/1743-7075-5-11. http:// nutritionandmetabolism.com/content/5/1/11/

73. Lutes LD, Winett RA, Barger SD, Wojcik JR, Herbert WG, Nickols-Richardson SM, Anderson ES: Small changes in nutrition and physical activity promote weight loss and maintenance: 3-month evidence from the ASPIRE randomized trial. Ann Behav Med 2008, 35:351-357.

74. Mahon AK, Flynn MG, Stewart LK, McFarlin BK, Iglay HB, Mattes RD, Lyle RM, Considine RV, Campbell WW: Protein intake during energy restriction: effects on body composition and markers of metabolic and cardiovascular health in postmenopausal women. J Am Coll Nutr 2007 26:182-189.

75. Masley SC, Weaver W, Peri G, Phillips SE: Efficacy of lifestyle changes in modifying practical markers of wellness and aging. Altern Ther Health Med 2008, 14:24-29.

76. McConnon A, Kirk SF, Cockroft JE, Harvey EL, Greenwood DC, Thomas JD, Ransley JK, Bojke L: The Internet for weight control in an obese sample: results of a randomised controlled trial. BMC Health Serv Res 2007, 7:206.

77. McDoniel SO, Wolskee P, Shen J: Treating obesity with a novel hand-held device, computer software program, and Internet technology in primary care: the SMART motivational trial. Patient Educ Couns 2010, 79:185-191.

78. McKibbin CL, Patterson TL, Norman G, Patrick K, Jin H, Roesch S, Mudaliar S, Barrio C, O'Hanlon K, Griver K, et al: A lifestyle intervention for older schizophrenia patients with diabetes mellitus: a randomized controlled trial. Schizophrenia Res 2006, 86:36-44.

79. Mefferd K, Nichols JF, Pakiz B, Rock CL: A cognitive behavioral therapy intervention to promote weight loss improves body composition and blood lipid profiles among overweight breast cancer survivors. Breast Cancer Res Treat 2007, 104:145-152.

80. Milano W, Grillo F, Del Mastro A, De Rosa M, Sanseverino B, Petrella C, Capasso A: Appropriate intervention strategies for weight gain induced by olanzapine: a randomized controlled study. Adv Ther 2007, 24:123-134.

81. Oldroyd JC, Unwin NC, White M, Mathers JC, Alberti KG: Randomised controlled trial evaluating lifestyle interventions in people with impaired glucose tolerance. Diabetes Res Clin Pract 2006, 72:117-127.

82. Paineau DL, Beaufils F, Boulier A, Cassuto DA, Chwalow J, Combris P, Couet C, Jouret B, Lafay L, Laville M, et al: Family dietary coaching to improve nutritional intakes and body weight control: a randomized controlled trial. Arch Pediatr Adolesc Med 2008, 162:34-43.

83. Pierce GL, Beske SD, Lawson BR, Southall KL, Benay FJ, Donato AJ, Seals DR: Weight loss alone improves conduit and resistance artery endothelial function in young and older overweight/obese adults. Hypertension 2008, 52:72-79.

84. Porsdal V, Beal C, Kleivenes OK, Martinsen EW, Lindstrom E, Nilsson H, Svanborg P: The Scandinavian Solutions for Wellness study - a two-arm observational study on the effectiveness of lifestyle intervention on subjective well-being and weight among persons with psychiatric disorders. BMC Psychiatry 2010, 10. doi:10.1186/1471-244X-10-42. http://biomedcentral.com/1471-244X/10/42/.

85. Poulin MJ, Chaput JP, Simard V, Vincent P, Bernier J, Gauthier Y, Lanctot G, Saindon J, Vincent A, Gagnon S, Tremblay A: Management of antipsychoticinduced weight gain: prospective naturalistic study of the effectiveness of a supervised exercise programme. Aust NZ J Psychiatry 2007, 41:980-989.

86. Racette SB, Weiss EP, Villareal DT, Arif H, Steger-May K, Schechtman KB, Fontana L, Klein S, Holloszy JO, Washington University School of Medicine CG: One year of caloric restriction in humans: feasibility and effects on body composition and abdominal adipose tissue. J Gerontol A Biol Sci Med Sci 2006, 61:943-950.

87. Racette SB, Deusinger SS, Inman CL, Burlis TL, Highstein GR, Buskirk TD, Steger-May K, Peterson LR: Worksite opportunities for wellness (WOW): effects on cardiovascular disease risk factors after 1 year. Prev Med 2009, 49:108-114.

88. Rodearmel SJ, Wyatt HR, Barry MJ, Dong F, Pan D, Israel RG, Cho SS, McBurney MI, Hill JO: A family-based approach to preventing excessive weight gain. Obesity 2006, 14:1392-1401.

89. Roumen C, Corpeleijn E, Feskens EJ, Mensink M, Saris WH, Blaak EE: Impact of 3-year lifestyle intervention on postprandial glucose metabolism: the SLIM study. Diabetes Med 2008, 25:597-605.

90. Samuel-Hodge CD, Keyserling TC, Park S, Johnston LF, Gizlice Z, Bangdiwala SI: A randomized trial of a church-based diabetes self-management program for African Americans with type 2 diabetes. Diabetes Educ 2009, 35:439-454.

91. Sarsan A, Ardic F, Ozgen M, Topuz O, Sermez Y: The effects of aerobic and resistance exercises in obese women. Clin Rehabil 2006, 20:773-782.

92. Sartorelli DS, Sciarra EC, Franco L, Cardoso MA: Beneficial effects of shortterm nutritional counselling at the primary health-care level among Brazilian adults. Pub Health Nutr 2005, 8:820-825.

93. Schwab U, Seppanen-Laakso T, Yetukuri L, Agren J, Kolehmainen M, Laaksonen DE, Ruskeepaa AL, Gylling H, Uusitupa M, Oresic M, Group GS: Triacylglycerol fatty acid composition in diet-induced weight loss in subjects with abnormal glucose metabolism-the GENOBIN study. PLos One 2008, 3:e2630.

94. Stahre L, Hallstrom T: A short-term cognitive group treatment program gives substantial weight reduction up to 18 months from the end of treatment. A randomized controlled trial. Eating Weight Disord 2005, 10:51-58.

95. Straznicky NE, Lambert EA, Nestel PJ, McGrane MT, Dawood T, Schlaich MP, Masuo K, Eikelis N, de Courten B, Mariani JA, et al: Sympathetic neural adaptation to hypocaloric diet with or without exercise training in obese metabolic syndrome subjects. Diabetes 2010, 59:71-79.

96. Subak LL, Whitcomb E, Shen H, Saxton J, Vittinghoff E, Brown JS: Weight loss: a novel and effective treatment for urinary incontinence. J Urology 2005, 174:190-195.

97. Svendsen M, Blomhoff R, Holme I, Tonstad S: The effect of an increased intake of vegetables and fruit on weight loss, blood pressure and antioxidant defense in subjects with sleep related breathing disorders. Eur J Clin Nutr 2007, 61:1301-1311. 
98. Thomson CA, Rock CL, Giuliano AR, Newton TR, Cui H, Reid PM, Green TL, Alberts DS, Women's Healthy E, Living Study G: Longitudinal changes in body weight and body composition among women previously treated for breast cancer consuming a high-vegetable, fruit and fiber, low-fat diet. Eur J Nutr 2005, 44:18-25.

99. Thoolen BJ, de Ridder D, Bensing J, Gorter K, Rutten G: Beyond good intentions: The role of proactive coping in achieving sustained behavioural change in the context of diabetes management. Psychol Health 2009, 24:237-254.

100. Toobert DJ, Strycker LA, Glasgow RE, Barrera M Jr, Angell K: Effects of the mediterranean lifestyle program on multiple risk behaviors and psychosocial outcomes among women at risk for heart disease. Ann Behav Med 2005, 29:128-137.

101. Torres SJ, Nowson CA: Effect of a weight-loss program on mental stressinduced cardiovascular responses and recovery. Nutrition 2007, 23:521-528.

102. Tully MA, Cupples ME, Chan WS, McGlade K, Young IS: Brisk walking, fitness, and cardiovascular risk: a randomized controlled trial in primary care. Prev Med 2005, 41:622-628.

103. Tuomilehto HP, Seppa JM, Partinen MM, Peltonen M, Gylling H, Tuomilehto JO, Vanninen EJ, Kokkarinen J, Sahlman JK, Martikainen T, et al: Lifestyle intervention with weight reduction: first-line treatment in mild obstructive sleep apnea. Am J Respir Crit Care Med 2009, 179:320-327.

104. Vissers D, Verrijken A, Mertens I, Van Gils C, Van de Sompel A, Truijen S, Van Gaal L: Effect of long-term whole body vibration training on visceral adipose tissue: a preliminary report. Obesity Facts 2010, 3:93-100.

105. von Gruenigen VE, Coumeya KS, GibbonS HE, Kavanagh MB, Waggoner SE, Lemer E: Feasibility and effectiveness of a lifestyle intervention program in obese endometrial cancer patients: A randomized trial. Gynecol Oncol 2008, 109:19-26.

106. Weiss EP, Villareal DT, Racette SB, Steger-May K, Premachandra BN, Klein S, Fontana L: Caloric restriction but not exercise-induced reductions in fat mass decrease plasma triiodothyronine concentrations: a randomized controlled trial. Rejuvenation Res 2008, 11:605-609.

107. Werkman A, Hulshof PJM, Stafleu A, Kremers SPJ, Kok FJ, Schouten EG, Schuit AJ: Effect of an individually tailored one-year energy balance programme on body weight, body composition and lifestyle in recent retirees: a cluster randomised controlled trial. BMC Public Health 2010, 10. doi:10.1186/1471-2458-10-110. http://www.biomedcentral.com/14712458/10/110.

doi:10.1186/1471-2288-12-120

Cite this article as: Waters et al:: Weight change in control group participants in behavioural weight loss interventions: a systematic review and meta-regression study. BMC Medical Research Methodology $201212: 120$

\section{Submit your next manuscript to BioMed Central and take full advantage of:}

- Convenient online submission

- Thorough peer review

- No space constraints or color figure charges

- Immediate publication on acceptance

- Inclusion in PubMed, CAS, Scopus and Google Scholar

- Research which is freely available for redistribution 